Cite this: J. Mater. Chem. A, 2014, 2, 9626

Received 27th March 2014

Accepted 14th April 2014

DOI: $10.1039 / c 4 t a 01476 f$

www.rsc.org/MaterialsA

\section{Zinc oxide films grown by galvanic deposition from 99\% metals basis zinc nitrate electrolyte}

\author{
S. Calnan, ${ }^{\text {a }}$ W. Riedel, ${ }^{\text {ab }}$ S. Gledhill, ${ }^{\text {ab }}$ B. Stannowski, ${ }^{a}$ R. Schlatmann ${ }^{\text {ac }}$ and \\ M. Ch. Lux-Steiner ${ }^{\text {ab }}$
}

\begin{abstract}
The use of relatively low purity zinc nitrate for electrochemical deposition of compact $\mathrm{ZnO}$ films is attractive for large scale production because of the cost saving potential. $\mathrm{ZnO}$ films were grown on $\mathrm{SnO}_{2}: \mathrm{F}$ and magnetron sputtered $\mathrm{ZnO}: \mathrm{Al}$ templates using a three electrode potentiostatic system in galvanic mode. The electrolyte consisted of a $0.1 \mathrm{M}$ zinc nitrate solution (either $99.998 \%$ or $99 \%$ purity) and $1 \mathrm{mM}$ aluminium nitrate for extrinsic doping, when required. Moderate deposition rates of up to $0.9 \mathrm{~nm} \mathrm{~s}^{-1}$ were achieved on $\mathrm{ZnO}: \mathrm{Al}$ templates with lower rates of up to $0.5 \mathrm{~nm} \mathrm{~s} \mathrm{~s}^{-1}$ on $\mathrm{SnO}_{2}: \mathrm{F}$ templates. Observation of SEM images of the films revealed a wall-like morphology whose lateral thickness (parallel to the substrate) reduced as aluminium was added to the system either in the electrolyte or from the substrate. However, pre-deposition activation of the template by applying a negative voltage (approximately $-2 \mathrm{~V}$ ) allowed the growth of compact films even for the low purity electrolyte. The optical band gap energy of intrinsically doped films was lower than that of the Al doped films. The composite electrical conductivity of all the films studied, as inferred from sheet resistance and Hall effect measurements of the $\mathrm{ZnO} /$ template stacks was much less than that of the uncoated templates. A strong $E_{2}$ (high) mode at around $437 \mathrm{~cm}^{-1}$ was visible in the Raman spectra for most films confirming the formation of $\mathrm{ZnO}$. However, both the Raman modes and XRD reflections associated with wurtzite $\mathrm{ZnO}$ diminished for the Al doped films indicating a high level of mainly oxygen related defects. Based on these data, further studies are underway to improve the doping efficiency of aluminium, the crystalline structure and thus the conductivity of such films.
\end{abstract}

\section{Introduction}

Zinc oxide is a technologically important material that is used as a transparent conductor in solar cells, thin film transistors, light emitting diodes and as an emitter in all oxide solar cells. Typically for each application, a specific restriction on the deposition method may be imposed such as an upper limit on the processing temperature to avoid damage of the already existing materials in the devices. In an industrial setting, there is an additional requirement to minimise fabrication costs by using high deposition rates and/or lower priced equipment and low raw material costs.

The best combination of high transmittance and conductivity in ZnO films is usually obtained by vacuum based physical vapour deposition (PVD) processes such as pulsed laser deposition (PLD) ${ }^{1}$ and magnetron sputtering. ${ }^{2}$ However, more flexibility in doping the material may be achieved by the use of chemical vapour

${ }^{a}$ Helmholtz-Zentrum für Materialien und Energie GmbH, Hahn-Meintner Platz 1, 14109 Berlin, Germany. E-mail: sonya.calnan@helmholtz-berlin.de

${ }^{b}$ Fachbereich Physik, Freie Universität Berlin, Arnimallee 14, 14195 Berlin, Germany ${ }^{c}$ Fachbereich 1 Ingenieurwissenschaften I, University of Applied Sciences (HTW) Berlin, Wilhelminenhofstraße 75 A, 12459 Berlin, Germany deposition under low pressure where the use of toxic or pyrophoric $^{3}$ precursors is almost unavoidable. Since around 2000, interest has risen in solution based methods to grow $\mathrm{ZnO}$ films such as electrochemical deposition (ECD) ${ }^{4-14}$ chemical bath deposition, ${ }^{15,16}$ and sol-gel based deposition techniques, ${ }^{17}$ to overcome the restrictions of physical and chemical vapour based production. Electrochemical deposition in particular, is a mature technology for industrial metal plating of items ranging from car parts to semiconductor devices. It follows naturally that researchers and producers of metal oxides find interest in this technique. Indeed, by using electrochemical deposition, the morphology of $\mathrm{ZnO}$ can be tuned from 2-dimensional films to 3-dimensional nano-structures such as rods, leaflets, sheets, walls, etc. ${ }^{18}$ As a result, electrochemically deposited $\mathrm{ZnO}$, in its diverse shapes, has found application in different types of photovoltaic devices for example, thin film silicon solar cells, ${ }^{19}$ all

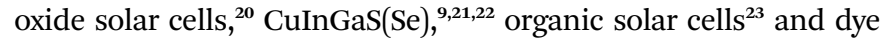
sensitized solar cells. ${ }^{24}$ However, the two main drawbacks of electrochemical depositions are the requirement for a conductive substrate and high sensitivity to the purity of the precursors.

For application as an electrode in optoelectronic devices such as solar cells, it is important that the ZnO film is highly conductive to minimise resistive losses. A survey of electrical 
parameters reported in the literature for electrochemically grown $\mathrm{ZnO}$ films is presented in Table 1.

The resistivity of intrinsically doped $\mathrm{ZnO}$ films grown by electrochemical deposition ranges from 3-1000 $\Omega \mathrm{cm}$ (ref. 12 and 14) and even after vacuum annealing the value of $3 \times$ $10^{-2} \Omega \mathrm{cm}$ (ref. 14) remains much higher than that demanded for device application as an electrode because of the low carrier concentration and mobility. The data for extrinsically doped films are very scarce, but values of $2-7.8 \times 10^{-3} \Omega \mathrm{cm}$ were reported using chlorine ${ }^{9}$ and boron. ${ }^{6}$ We note that the lower value of $2 \times 10^{-3} \Omega \mathrm{cm}$ was determined indirectly from sheet resistance measurements ${ }^{9}$ while the higher value was obtained for a ZnO:B film grown on a less conductive substrate. ${ }^{6}$ Unfortunately, no independent group has reported a replication of the latter result till now. The survey illustrates the well-known fact that the electrical conductivity of solution processed $\mathrm{ZnO}$ is relatively poor. It also provides evidence that although intrinsic ZnO grown by ECD presents compact crystalline films, the mobility is rather lower than would be expected.

In contrast, a very few reports on aluminium doped ECDgrown ZnO films have been published. Most work about ECDgrown $\mathrm{ZnO}$ :Al tends to focus on the surface morphology of the films and does not address the possible reasons for the disruption of the crystalline structure by the inclusion of aluminium. In most cases the authors observed a disruption of the crystalline film structure and morphology as $\mathrm{Al}$ was introduced into the electrolyte for doping. ${ }^{11,13}$ Only very few reports address the electrical properties of ECD-grown ZnO:Al films. ${ }^{13}$

The ability to optimise high conductivity together with the structure of electrochemically deposited $\mathrm{ZnO}$ films is a delicate balance act since on one hand it is attractive to flexibly change the morphology as required, but on the other hand, the parameter window for a specific morphology is rather narrow. The high sensitivity of the process to impurities is particularly challenging because semi-conducting films rely on intentionally added impurities to enhance specific properties. For example, to achieve the near metal conductivity usually required in solar cells, $\mathrm{ZnO}$ must be extrinsically doped to ensure a temperature stable conductivity, at least, around room temperature. Additionally, although compact films can be easily obtained via high purity precursors, the cost can be exorbitant. The use of relatively low purity zinc nitrate for electrochemical deposition of compact $\mathrm{ZnO}$ films is attractive for large scale production because of the cost saving potential. Therefore, this study investigates the possibility of growing extrinsically doped conductive compact $\mathrm{ZnO}$ films by electrochemical deposition using a low cost, low purity precursor.

\section{Experimental methods}

Glass sheets coated with $\mathrm{SnO}_{2}: \mathrm{F}$ and magnetron sputtered $\mathrm{ZnO}$ :Al of dimensions $8.75 \mathrm{~cm}^{2}$, to be used as templates, were successively cleaned in an ultra-sonic bath using acetone, ethanol and ultrahigh purity water $(18.2 \mathrm{M} \Omega)$ then dried with nitrogen. The templates were then coated with $\mathrm{ZnO}$ using galvanic deposition in a three electrode electrochemical cell using a platinum wire $\left(E_{0}=+1.2 \mathrm{~V}\right.$ versus a standard hydrogen

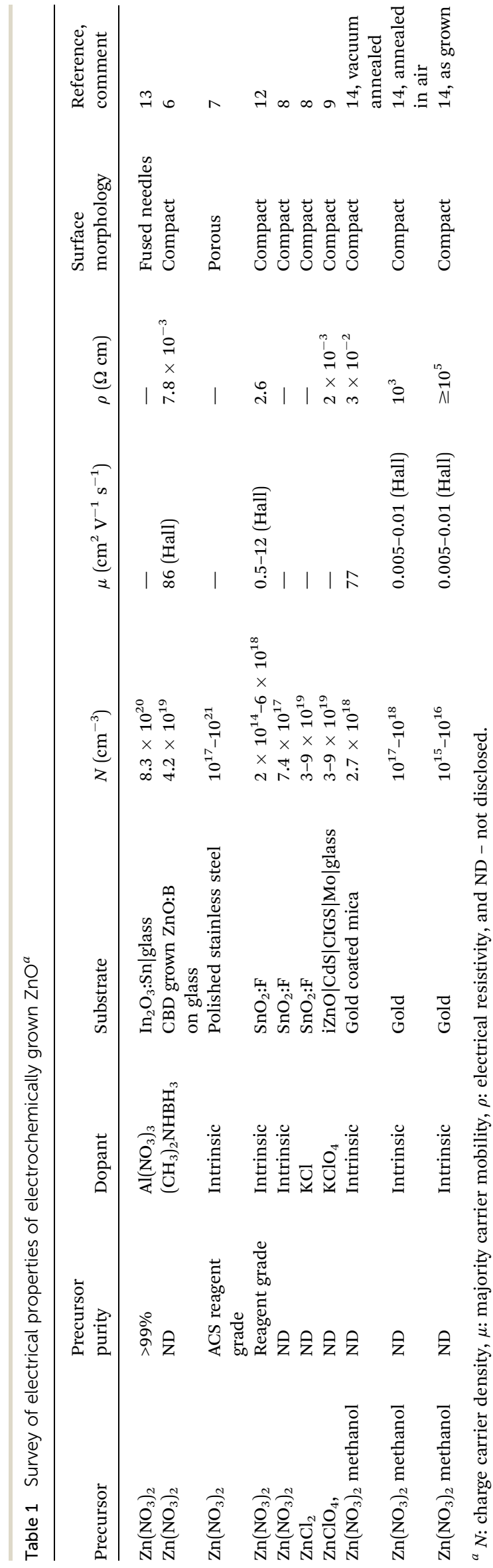


electrode) as a pseudo-reference electrode and a platinum sheet as the counter electrode. All chemicals were purchased from Alfa Aesar and the different electrolytes consisted of a $0.1 \mathrm{M}$ zinc nitrate solution (either $99.998 \%$ or $99 \%$ purity) and $1 \mathrm{mM}$ aluminium nitrate $(99.999 \%$ purity) for extrinsic doping, when required. We chose high purity aluminium nitrate as the doping salt since apart from aluminium, no other foreign elements are introduced in the electrolyte. In contrast, although the survey shows that chlorine doping appears to provide compact films with large crystalline grains, the conductivity tends to deteriorate with time after exposure to the environment. ${ }^{9}$ All solutions were made using ultrapure water with an electrical resistance of 18.2 $\mathrm{M} \Omega$ from a Millipore Milli-Q purifier. The electrolyte was heated to $62{ }^{\circ} \mathrm{C}$ and was constantly stirred at $90 \mathrm{rpm}$ using a magnetic stirrer during the $\mathrm{ZnO}$ film depositions. A schematic of the electrochemical deposition set-up used to grow the $\mathrm{ZnO}$ films is shown in Fig. 1.

For one set of films, a current density of $-0.5 \mathrm{~mA} \mathrm{~cm}{ }^{-2}$ was driven through the template for $900 \mathrm{~s}$ while for the second set, an activation step at $-2.06 \mathrm{~V}$ for $10 \mathrm{~s}$ was introduced before applying a current density of $-0.25 \mathrm{~mA} \mathrm{~cm}^{-2}$ for $1200 \mathrm{~s}$. The application of a negative potential prior to the deposition, which forms an ultra-thin metallic zinc layer on the template, was done to increase the nucleation density for $\mathrm{ZnO}$ growth., ${ }^{\mathbf{5}}$ After deposition, all films were rinsed with de-ionised water and heated in air for 30 minutes at $300{ }^{\circ} \mathrm{C}$ to completely convert any $\mathrm{Zn}(\mathrm{OH})_{2}$ to $\mathrm{ZnO}$. In addition, cyclic voltammetry $(\mathrm{CV})$ was performed on the two types of templates at a sweep rate of $0.1 \mathrm{~V} \mathrm{~s}^{-1}$ with a step size of $10 \mathrm{mV}$ and switching voltages $\sim \pm 3 \mathrm{~V}$ with the same variation of the electrolyte, as above, but without stirring. All galvanic depositions and CV studies were carried out using a Compactstat potentio-galvanostat and IviumSoft software for process control, both, from Ivium Technologies.

The deposited film thickness was determined by stylus profilometry (D-120, KLA-TENCOR) at a step etched through ZnO. Transmittance spectra were collected using a spectrophotometer (LAMBDA 1050 from PerkinElmer) fitted with an integrating sphere. Sheet resistance was measured using a RM3-AR four point probe from Jandel Engineering Ltd. Room temperature Hall effect measurements of the layer stack were made in

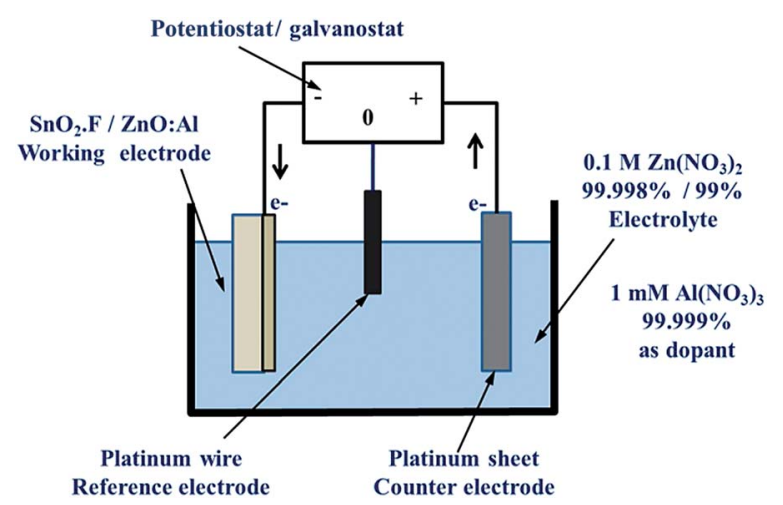

Fig. 1 Schematic of the electrochemical deposition set-up used for the $\mathrm{ZnO}$ films presented here. the Van der Pauw configuration using a 0.56 T magnetic field for selected films on an HMS-3000 Hall Measurement System (Ecopia. S. Korea). Four point probe and Hall effect measurements on multilayer films such as those in this study, made under the assumption of a constant carrier concentration along the film thickness, were not expected to be quantitatively accurate but were used as a qualitative indicator of trends. The surface and crosssections of the $\mathrm{ZnO}$ films after deposition were examined using a scanning electron microscope (S-4100 from HITACHI). X-ray diffraction measurements were carried out on a Bruker X8 diffractometer using $\mathrm{Cu} \mathrm{K} \alpha$ radiation $(\lambda=1.5406 \AA)$ to study the crystal structure of the films. Grazing incidence at $0.25^{\circ}$ was used to increase the signal from the layers of interest by partially suppressing the much stronger reflections from the $\mathrm{SnO}_{2}: \mathrm{F}$ templates. Raman spectra were acquired at room temperature by a Dilor/ISA LabRAM 010 system using an argon ion laser excitation at $458 \mathrm{~nm}$.

\section{Results}

\section{Cyclic voltammetry in different electrolyte solutions}

The cyclic voltammograms for the different types of electrolyte solutions used to grow $\mathrm{ZnO}$ films in this study are shown in Fig. 2. The CV curves exhibit distinct differences depending on the purity of the $\mathrm{Zn}\left(\mathrm{NO}_{3}\right)_{2}$ precursor regardless of the substrate type. During the first scan from 0 to $+3 \mathrm{~V}$ an anodic peak can be seen around $+2.4 \mathrm{~V}$ on $\mathrm{ZnO}: \mathrm{Al}$ and $+2.6 \mathrm{~V}$ on $\mathrm{SnO}_{2}: \mathrm{F}$ using the $99 \%$ purity electrolyte. When the voltage sweep was then reversed between $+3 \mathrm{~V}$ and $0 \mathrm{~V}$, a corresponding anodic peak can be seen at a slightly lower positive voltage. At least one additional anodic peak is visible only on the $\mathrm{SnO}_{2}: \mathrm{F}$ cathode implying that the reaction with low purity $\mathrm{ZnO}$ also includes species from the template. In contrast, on the addition of $\mathrm{Al}$, no extra peaks are seen either on $\mathrm{ZnO}: \mathrm{Al}$ or on $\mathrm{SnO}_{2}: \mathrm{F}$, regardless of the electrolyte purity. In the reverse scan from $+3 \mathrm{~V}$ to $-3 \mathrm{~V}$, the onset of high cathodic current shifts to more negative voltage for the electrolytes without $\mathrm{Al}^{3+}$ compared to the doped case, indicating that a less conductive $\mathrm{ZnO}$ film is formed on the surface. Also in this region, the cathodic peaks for the low purity electrolytes are fewer than the corresponding anodic peaks seen in the previous sweep indicating that some species in the electrolyte were irreversibly oxidized during the anodic step. Since the anodic peaks do not appear for the high purity films, they can be attributed to impurities. According to the supplier's analysis certificates, the $99 \% \mathrm{Zn}\left(\mathrm{NO}_{3}\right)_{2}$ contained relatively high amounts of sulphates (1000 ppm) and lead (500 ppm). Neither impurity could be traced in either the $99.998 \% \mathrm{Zn}\left(\mathrm{NO}_{3}\right)_{2}$ or the 99.999\% $\mathrm{Al}\left(\mathrm{NO}_{3}\right)_{3}$ by inductively coupled plasma mass spectrometry for both, as well as by atomic absorption spectroscopy for the former.

\section{Film thickness and opto-electronic properties}

The film thickness and deposition rate of all films prepared in this study as well as the sheet resistance, carrier concentration and Hall mobility of selected films are presented in Table 2. 


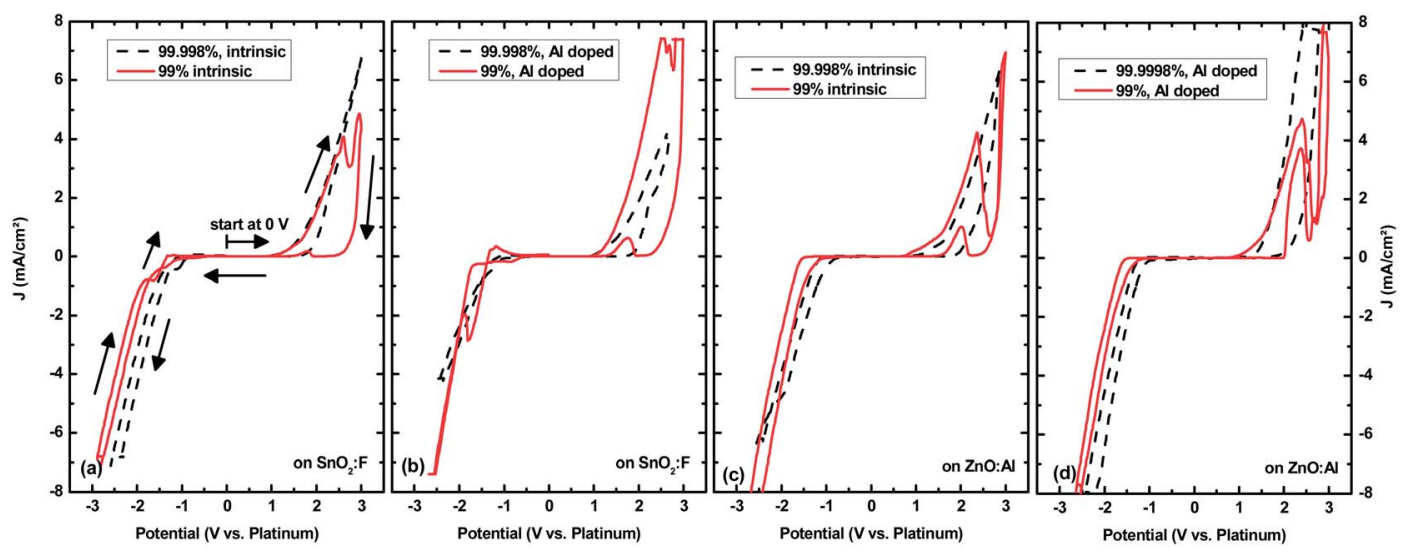

Fig. 2 Cyclic voltammograms of (a) intrinsic Zn salt electrolytes with different purity and (b) Zn salt electrolytes of different purity with additional $\mathrm{Al}^{3+}$ ions, on $\mathrm{SnO}_{2}: \mathrm{F}$ and on $\mathrm{ZnO}$ :Al templates, (c) intrinsic- and (d) $\mathrm{Al}^{3+}$ doped $\mathrm{Zn}$ salt electrolytes of different purity. The arrows in (a) indicate the sweep direction.

Table 2 Template type, zinc precursor purity, molar amount of the Al dopant added to the electrolyte, pre-deposition template activation time $t$, deposition rate $R_{\mathrm{D}}$, film thickness $d$, four point sheet resistance $R_{\mathrm{S}}$, majority carrier concentration $N_{\mathrm{e}}$ and Hall mobility $\mu$ of the different electrochemically grown $\mathrm{ZnO}$ films. The thickness of the template was added to that of the electrochemically grown $\mathrm{ZnO}$ to determine the Hall parameters

\begin{tabular}{|c|c|c|c|c|c|c|c|c|}
\hline Template & $\mathrm{Zn}\left(\mathrm{NO}_{3}\right)_{2}$ purity & $\mathrm{Al}\left(\mathrm{NO}_{3}\right)_{3}(\%)$ & $t(\mathrm{~s})$ & $R_{\mathrm{D}}\left(\AA \mathrm{s}^{-1}\right)$ & $d(\mathrm{~nm})$ & $R_{\mathrm{S}}(\mathrm{k} \Omega)$ & $N_{\mathrm{e}}\left(10^{20} \mathrm{~cm}^{-3}\right)$ & $\mu\left(\mathrm{cm}^{2} \mathrm{~V}^{-1} \mathrm{~s}^{-1}\right)$ \\
\hline $\mathrm{SnO}_{2}: \mathrm{F}$ & - & - & - & - & 791 & 0.012 & 1.7 & 41.0 \\
\hline \multirow[t]{3}{*}{$\mathrm{SnO}_{2}: \mathrm{F}$} & 99.998 & 0 & 10 & 3.1 & 377 & - & - & - \\
\hline & & 0 & 0 & 7.9 & 709 & - & 0.9 & 28.2 \\
\hline & & 0.1 & 10 & 3.6 & 427 & 150 & - & - \\
\hline \multirow[t]{4}{*}{$\mathrm{SnO}_{2}: \mathrm{F}$} & 99 & 0 & 10 & 2.8 & 341 & - & - & - \\
\hline & & 0 & 0 & 5.6 & 503 & - & 0.1 & 38.8 \\
\hline & & 0.1 & 10 & 1.7 & 202 & 600 & - & - \\
\hline & & 0.1 & 0 & 4.9 & 442 & - & 0.1 & 38.9 \\
\hline ZnO:Al & - & - & - & - & 876 & 0.008 & 3.9 & 26.4 \\
\hline \multirow[t]{2}{*}{ ZnO:Al } & 99.998 & 0 & 10 & 3.0 & 357 & - & - & - \\
\hline & & 0.1 & 10 & 5.1 & 614 & 100 & - & - \\
\hline \multirow[t]{4}{*}{ ZnO:Al } & 99 & 0 & 10 & 3.4 & 405 & - & - & - \\
\hline & & 0 & 0 & 8.8 & 789 & - & 1.3 & 27.9 \\
\hline & & 0.1 & 10 & 2.9 & 350 & 1000 & - & - \\
\hline & & 0.1 & 0 & 7.3 & 659 & - & 1.9 & 28.2 \\
\hline
\end{tabular}

Using a current density of $0.5 \mathrm{~mA} \mathrm{~cm}{ }^{-2}$, moderate deposition rates of up to $0.9 \mathrm{~nm} \mathrm{~s}^{-1}$ and $0.7 \mathrm{~nm} \mathrm{~s}^{-1}$ were achieved on $\mathrm{ZnO}: \mathrm{Al}$ and $\mathrm{SnO}_{2}: \mathrm{F}$ templates, respectively, which reduced to $0.3 \mathrm{~nm} \mathrm{~s}^{-1}$ on both templates for a current density of $0.25 \mathrm{~mA}$ $\mathrm{cm}^{-2}$. In general, the film thickness is lower for the same zinc nitrate purity once $\mathrm{Al}^{3+}$ ions are introduced into the electrolyte. Sheet resistance on the films could only be measured for the samples treated with an activation step prior to deposition and with doping. The sheet resistance values were about 100$1000 \mathrm{k} \Omega$ with the values on the lower end observed for high purity $\mathrm{Zn}\left(\mathrm{NO}_{3}\right)_{2}$ precursors. The effective carrier concentration of the $\mathrm{ZnO} /$ template stacks was less than that of the bare templates. Slight increases in the effective carrier concentration could be observed for samples made with the electrolyte containing aluminium. The effective Hall mobility of the $\mathrm{ZnO} /$ $\mathrm{SnO}_{2}: \mathrm{F}$ stacks was lower than that of the bare $\mathrm{SnO}_{2}: \mathrm{F}$ while that on the $\mathrm{ZnO} / \mathrm{ZnO}: \mathrm{Al}$ stacks was higher than on the bare $\mathrm{ZnO}: \mathrm{Al}$ template by roughly $10 \%$.
The total transmission spectra of selected $\mathrm{ZnO}$ films grown by electro-deposition on $\mathrm{SnO}_{2}: \mathrm{F}$ and $\mathrm{ZnO}: \mathrm{Al}$ templates are presented in Fig. 3.

The spectra of the templates are also shown for the respective group of electrochemically grown $\mathrm{ZnO}$ films. Note that while the ZnO:Al template had a smooth surface, the $\mathrm{SnO}_{2}$ :F surface was rough and thus the measured total transmission was slightly reduced by scattering losses. ${ }^{25}$ All electrochemically films were transparent in the visible range although the transmittance, as measured for some films, was reduced by diffuse scattering losses from the high roughness of the final $\mathrm{ZnO}$ surface. Pre-deposition activation caused an increase in the measured transmittance of the films as the diffuse scattering was slightly reduced by the smoother surface morphology as will be shown later in the results for SEM. The films grown in high purity $\mathrm{Zn}$ salt exhibited a much smaller optical bandgap compared to the template and the films grown in the less pure electrolyte and with $\mathrm{Al}^{3+}$ doping. 

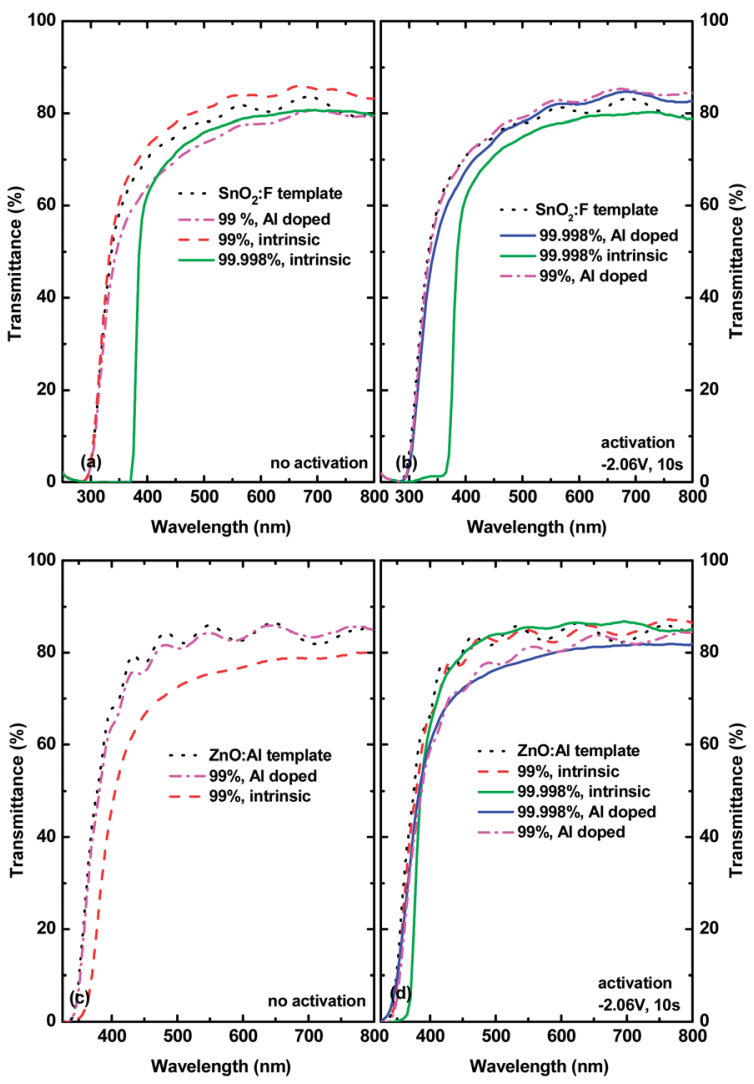

Fig. 3 Transmittance spectra of electrochemically deposited $\mathrm{ZnO}$ films grown on (a) and (b) $\mathrm{SnO}_{2}: \mathrm{F}$ and (c) and (d) $\mathrm{ZnO}$ :Al templates, with and without a pre-deposition activation of $-2.06 \mathrm{~V}$ for $10 \mathrm{~s}$. The spectral range has been limited to an upper wavelength of $500 \mathrm{~nm}$ to allow a clearer inspection of the variation of the optical band-gap of the films.

\section{Surface morphology}

The SEM images of a ZnO film grown with a high purity Zn electrolyte on $\mathrm{SnO}_{2}: \mathrm{F}$ as well as films grown with a lower purity Zn electrolyte, with and without doping, are shown in Fig. 4.

For comparison, the SEM images of the $\mathrm{ZnO}: \mathrm{Al}$ and $\mathrm{SnO}_{2}: \mathrm{F}$ templates are also included. It can be seen that reduced $\mathrm{Zn}\left(\mathrm{NO}_{3}\right)_{2}$ purity or the addition of $\mathrm{Al}$ ions to the electrolyte resulted in less compact films characterized by a wall-like structure whose lateral thickness (parallel to the substrate) reduced as aluminium was added to the system either in the electrolyte or from the substrate. In contrast, the film grown from the high purity $\mathrm{Zn}\left(\mathrm{NO}_{3}\right)_{2}$ on $\mathrm{SnO}_{2}: \mathrm{F}$ formed closely spaced grains that grew compactly as seen in the top view and crosssection view in Fig. 4(d) and (h), respectively.

The SEM images of various ZnO films grown with a $10 \mathrm{~s}$ potentiostatic activation step prior to galvanic deposition are shown in Fig. 5. It can be seen that the wall-like structure for less pure electrolyte and with doping was replaced by more compact films although the Al doped films have an irregular surface coverage with wall-like structures in some places (see for example the top left hand corner of Fig. 5(c)).

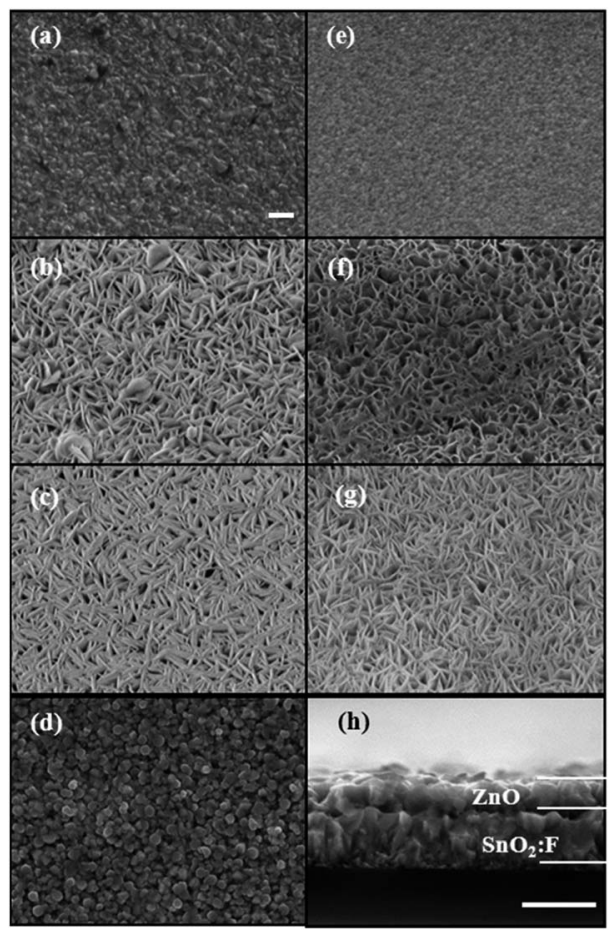

Fig. 4 Top view SEM images of (a) $\mathrm{SnO}_{2}: \mathrm{F}$ template, $\mathrm{ZnO}$ on $\mathrm{SnO}_{2}: \mathrm{F}$ from (b) $99 \% \mathrm{Zn}\left(\mathrm{NO}_{3}\right)_{2}$ with $\mathrm{Al}$ doping, (c) $99 \% \mathrm{Zn}\left(\mathrm{NO}_{3}\right)_{2}$ and (d) 99.998\% $\mathrm{Zn}\left(\mathrm{NO}_{3}\right)_{2}$; (e) sputtered $\mathrm{ZnO}: \mathrm{Al}$ template, $\mathrm{ZnO}$ on $\mathrm{ZnO}: \mathrm{Al}$ template from (f) $99 \% \mathrm{Zn}\left(\mathrm{NO}_{3}\right)_{2}$ and (g) $99 \% \mathrm{Zn}\left(\mathrm{NO}_{3}\right)_{2}$ and (h) a crosssection SEM image of the film in (d). The deposition conditions were $-0.5 \mathrm{~mA} \mathrm{~cm}^{-2}$ applied current density, an electrolyte temperature of $62{ }^{\circ} \mathrm{C}$ with constant stirring at $90 \mathrm{rpm}$. The thick white bars represent a scale of $1 \mu \mathrm{m}$. Images in (a) to (g) have the same magnification.

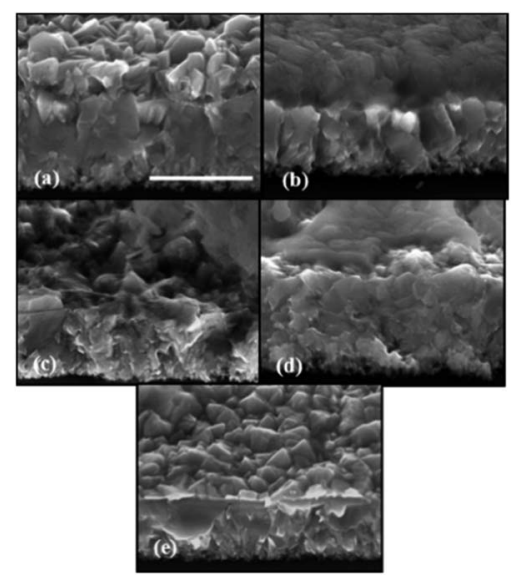

Fig. 5 Cross-section SEM images, with a $30^{\circ}$ tilt, of $\mathrm{ZnO}$ films grown on $\mathrm{SnO}_{2}:$ F templates from (a) $99.998 \% \mathrm{Zn}\left(\mathrm{NO}_{3}\right)_{2}$, (b) $99 \% \mathrm{Zn}\left(\mathrm{NO}_{3}\right)_{2}$, (c) $99.998 \% \mathrm{Zn}\left(\mathrm{NO}_{3}\right)_{2}$ with $\mathrm{Al}$ doping, (d) $99 \% \mathrm{Zn}\left(\mathrm{NO}_{3}\right)_{2}$ with $\mathrm{Al}$ doping and (e) a bare $\mathrm{SnO}_{2}: \mathrm{F}$ template for reference. The deposition conditions were $10 \mathrm{~s}$ potentiostatic activation, $-0.25 \mathrm{~mA} \mathrm{~cm}{ }^{-2}$ applied current density, an electrolyte temperature of $62{ }^{\circ} \mathrm{C}$ with constant stirring at $90 \mathrm{rpm}$. The thick white bar in (a) represents a length of $1 \mu \mathrm{m}$ and all images are of the same magnification. 


\section{Crystalline microstructure}

The XRD patterns for $\mathrm{ZnO}$ films grown by electrochemical deposition with a pre-deposition activation step on $\mathrm{SnO}_{2}: \mathrm{F}$ are presented in Fig. 6.

The respective XRD patterns for $\mathrm{ZnO}$ grown on $\mathrm{ZnO}$ :Al were also measured but are not presented since the strong $c$-axis orientation of the substrate prevented the observation of peaks attributable to the electrochemically grown films. The XRD peak positions corresponding to $\mathrm{SnO}_{2}$ and wurtzite $\mathrm{ZnO}$ are labelled using data from the literature. ${ }^{26,27}$ Reflections corresponding to the (100), (002) and (101) planes of wurtzite $\mathrm{ZnO}$ are visible for the films grown using the higher purity $\mathrm{Zn}\left(\mathrm{NO}_{3}\right)_{2}$ precursor. The XRD reflection peak intensity especially for the reflections of the (002) plane diminishes significantly for Al doping during deposition as also observed by other groups. ${ }^{11,13}$ The intrinsic film grown using $99 \% \mathrm{Zn}\left(\mathrm{NO}_{3}\right)_{2}$ only shows a reflection peak for the (002) texture that is shifted to lower angles and addition of $\mathrm{Al}$ to the solution completely suppresses the $\mathrm{ZnO}$ reflections (not shown).

\section{Raman spectroscopy}

The Raman spectra of selected $\mathrm{ZnO}$ films grown on $\mathrm{SnO}_{2}: \mathrm{F}$ and ZnO:Al templates without pre-deposition activation are shown in Fig. 7.

The positions of the Raman peaks originating from $\mathrm{SnO}_{2}: \mathrm{F}$ are marked with asterisks using data taken from the literature. ${ }^{28}$ The peak positions of Raman modes for wurtzite $\mathrm{ZnO}^{29}$ as well as anomalous modes that are usually not allowed for incidence perpendicular to the $c$-axis ${ }^{30}$ are marked using vertical dotted lines. A $\mathrm{E}_{2}$ (high) mode at $437 \mathrm{~cm}^{-1}$ is observed for all films grown by intrinsic electrolytes, on $\mathrm{SnO}_{2}: \mathrm{F}$ as a prominent peak, and on $\mathrm{ZnO}: \mathrm{Al}$ as an increase in the $\mathrm{E}_{2}$ (high)/ $\mathrm{A}_{1}(\mathrm{LO})$ intensity ratio compared to the template. The $\mathrm{E}_{2}$ (high) mode broadens in the case of $\mathrm{Al}$ doping on both templates. A weak $\mathrm{A}_{1}(\mathrm{TO})$ mode at $380 \mathrm{~cm}^{-1}$ is also observed for the intrinsic films on $\mathrm{SnO}_{2}: \mathrm{F}$ but cannot be resolved for films on $\mathrm{ZnO}$ :Al. A localized vibration

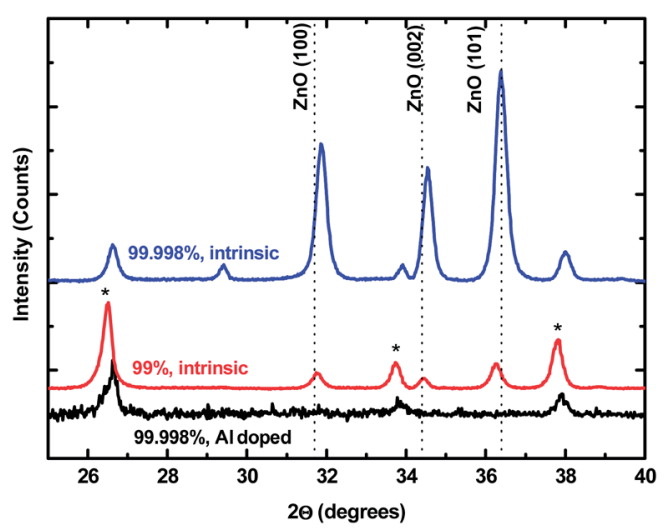

Fig. 6 X-ray diffraction patterns for electrochemically grown $\mathrm{ZnO}$ films on $\mathrm{SnO}_{2}: F$ templates. Peak positions for wurtzite $\mathrm{ZnO}$ are indicated by dotted lines while those corresponding to $\mathrm{SnO}_{2}$ are labelled with asterisks. Prior to the deposition, the substrate was activated by applying a negative bias of $-2.06 \mathrm{~V}$ relative to a platinum pseudo reference electrode for $10 \mathrm{~s}$.
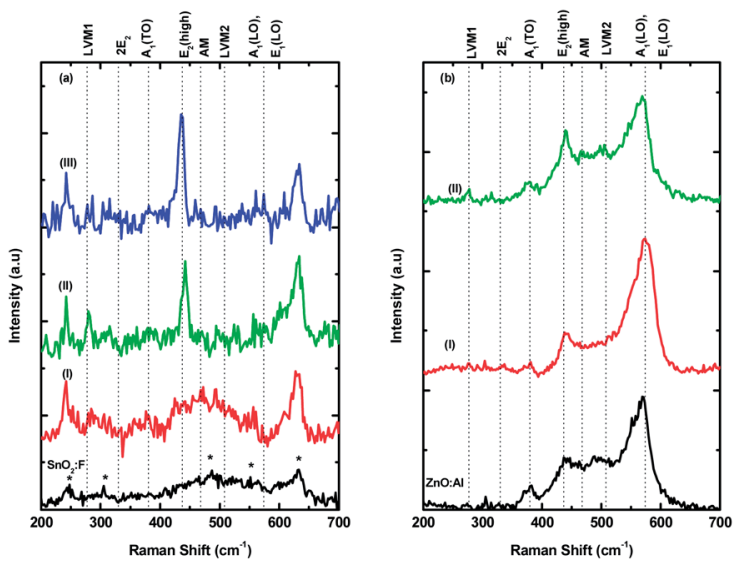

Fig. 7 Raman spectra for $\mathrm{ZnO}$ :Al films grown without pre-deposition activation on (a) $\mathrm{SnO}_{2}: \mathrm{F}$ and (b) $\mathrm{ZnO}: \mathrm{Al}$ templates. The labels on the curves correspond to films grown from (I) $99 \%$ purity electrolyte with Al doping, (II) $99 \%$ purity electrolyte without doping and (III) $99.998 \%$ purity electrolyte without doping. The peak positions for $\mathrm{ZnO}$ are indicated by the vertical dotted lines while those for $\mathrm{SnO}_{2}$ are marked by asterisks. Measurements were taken at room temperature with a Raman excitation wavelength of $458 \mathrm{~nm}$.

mode at $277 \mathrm{~cm}^{-1}$ (denoted as LVM1) was also visible for all the films. The Raman spectra for ZnO films grown with pre-deposition activation of the template are presented in Fig. 8. Again a strong $\mathrm{E}_{2}$ (high) response was observed for intrinsic films which then reduced with doping. Weak $\mathrm{A}_{1}(\mathrm{TO})$ modes were also seen for all films regardless of the type of electrolyte or template. A so-called additional mode AM at $468 \mathrm{~cm}^{-1}$ was observed for films grown on both substrates for the intrinsic low purity electrolyte and in the case of doping. Weak peaks corresponding to LVM1 at $277 \mathrm{~cm}^{-1}$ were observed for all films especially more clearly on the ZnO:Al template while only weak LVM2 peaks around $508 \mathrm{~cm}^{-1}$ were observed for all the Al-doped films.
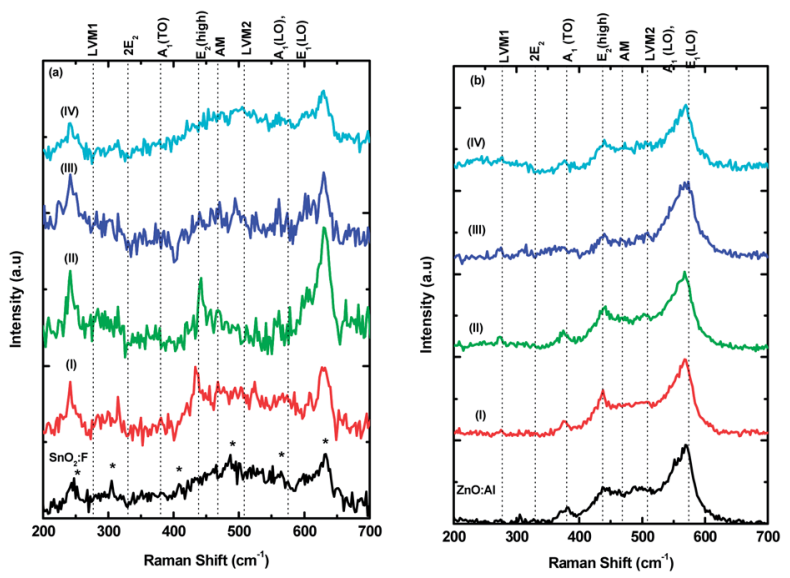

Fig. 8 Raman spectra for $\mathrm{ZnO}$ :Al films grown with pre-deposition activation on (a) $\mathrm{SnO}_{2}: \mathrm{F}$ and (b) $\mathrm{ZnO}: \mathrm{Al}$ templates. The spectra labels are assigned as follows: (I) $99.998 \%$, intrinsic; (II) $99 \%$, intrinsic; (III) 99.998\%, Al doped and (IV) 99\%, Al doped. The peak positions for ZnO are indicated by the vertical dotted lines while those for $\mathrm{SnO}_{2}$ are marked by asterisks. Measurements were taken at room temperature with a Raman excitation wavelength of $458 \mathrm{~nm}$. 


\section{Discussion}

For ZnO film growth without activation, electrolytes of low purity and with $\mathrm{Al}^{3+}$ ions resulted in a fibrous thin walled structure with weak $\mathrm{E}_{2}$ (high) Raman modes. The presence of the $\mathrm{Al}^{3+}$ dopant enhanced the conductivity and shifted the optical bandgap to lower wavelengths. The use of pre-deposition template activation resulted in more compact films for both low purity and doped electrolytes. The $\mathrm{ZnO}$ films grown from intrinsic electrolytes exhibited both XRD reflections and Raman modes characteristic of wurtzite $\mathrm{ZnO}$, whose intensity decreased for lower electrolyte purity and the films were highly resistive. For $\mathrm{Al}$ doped $\mathrm{ZnO}$ films, the crystalline order broke down and the $\mathrm{E}_{2}$ (high) Raman modes diminished although the conductivity was slightly improved compared to the intrinsically doped films.

We would like to emphasise that in this study, we do not consider the intrinsically doped $\mathrm{ZnO}$ films grown from high purity precursors as a benchmark TCO material. Firstly, the conductivity is insufficient despite the compact nature of the films and secondly, the transmission onset occurs at longer wavelengths than for films grown from solutions containing more impurity which, is undesirable for use in devices such as photovoltaic cells. These films were only included in the study to illustrate one of the desirable physical properties of TCO films, i.e. a compact structure caused by fused large sized grains which may promote high electron mobility. In general, a film with a compact structure and high crystallinity but low carrier concentration, does not achieve a conductivity value high enough for application as a low resistivity electrode. This effect was observed for intrinsically doped $\mathrm{ZnO}$ films grown by ECD, ${ }^{\mathbf{8 1 2 , 1 4}}$ CVD $^{3}$ and even PLD on sapphire. ${ }^{31}$ The only way to appreciably enhance the conductivity in $\mathrm{ZnO}$ is by doping it with an impurity and this is the route we have taken in this study.

The deposition rate of the films in this study was generally reduced as $\mathrm{Al}^{3+}$ ions were added to the electrolyte. The reduced deposition rate for $\mathrm{ZnO}: \mathrm{Al}$ compared to intrinsically doped $\mathrm{ZnO}$ has been attributed to promotion and hindrance, respectively, of growth in the $a$-direction (parallel to the substrate) and $c$-direction (perpendicular to the substrate), respectively for chemical bath deposited films. ${ }^{\mathbf{1 6}}$

Compact $\mathrm{ZnO}$ films have been grown on $\mathrm{SnO}_{2}: \mathrm{F}$ coated substrates from zinc nitrate by other groups using a high purity (99.999\% purity) zinc plate as an active anode. ${ }^{4}$ In that study, the lowest sheet resistance of $200 \Omega \mathrm{cm}$ was obtained with a very low current density of $0.05 \mathrm{~mA} \mathrm{~cm}^{-2}$ during the film deposition and since the film thickness was $2 \mu \mathrm{m}$, such a deposition is expected to last for several hours. Similarly to our case, the sheet resistance measured for those films included the contribution of the substrate and for comparable current densities, our values of sheet resistance on $\mathrm{ZnO}$ :Al were an order of magnitude higher because they were much thinner.

In general, the study of the electrical conductivity of electrochemically grown $\mathrm{ZnO}$ films has been largely neglected in the past because of the presence of a higher conductivity substrate.
In the survey of reported electrical properties of such films presented in Table 1, one can notice that these data are incomplete as they are mostly derived from indirect measurements such as Mott Schottky analysis of impedance spectroscopy measurements, ${ }^{7,8,13}$ current-voltage characteristics ${ }^{9,21}$ and the four point probe method. ${ }^{4,9}$ In a few cases, ${ }^{12,14,32}$ the films were transferred to an insulating substrate via a lift off technique developed by von Windheim. ${ }^{33}$ The transferred films could then be directly characterised by Hall effect measurements but the method is only reliable for transferring thick films $>5 \mu \mathrm{m}$ without damage. ${ }^{\mathbf{1 4 , 3 2}}$ Apart from the unusual result by Ishizaki et al., ${ }^{6}$ none of the films show appreciable conductivity although the carrier concentration of the films is close to that of high conductivity films grown by sputtering ${ }^{2}$ and CVD. ${ }^{3}$ In our films as well as those presented in Table $1, \mathrm{Al}^{3+}$ doping provides extra free electrons to the film, however, the resistivity remains rather high compared to physical or chemical vapour grown films as a result of the rather low mobility. This effect has also been observed for films grown by CBD. ${ }^{16}$

The location of the band gap edge at lower energies for intrinsically doped $\mathrm{ZnO}$ compared to those extrinsically doped with aluminium, is well known and has been observed for films grown by various methods such as electrochemical deposition, ${ }^{\mathbf{1 3}}$ sputtering, ${ }^{2}$ pulsed laser deposition, ${ }^{34}$ chemical vapour deposition $^{3}$ and sol gel processing. ${ }^{35}$ Comparisons of optical spectra from different sources are difficult, since it is normally not disclosed whether the reported transmission includes or excludes the substrate, however, a qualitative comparison can be made. On this basis, the visible transmittance of our films was similar to or even better than that observed by others., ${ }^{5,23}$ Since the films grown from the higher purity intrinsic $\mathrm{Zn}\left(\mathrm{NO}_{3}\right)_{2}$ solution showed a transmission onset at around $370 \mathrm{~nm}$, irrespective of the use or omission of the pre-deposition activation step, we can conclude that their carrier concentration was well below $10^{19} \mathrm{~cm}^{-3}$ (ref. 36) while that of impurity doped films and those made with low purity $\mathrm{Zn}\left(\mathrm{NO}_{3}\right)_{2}$, including the intrinsically doped ones was higher. Films with a rough surface morphology, caused by large grains tend to be hazy and thus there are errors associated with measuring the total transmission of the films as already mentioned.

Other authors have also observed, just like we did, the tendency for electrochemically deposited $\mathrm{ZnO}$ :Al to grow as sheets or walls rather than as nano-rods or compact films. ${ }^{\mathbf{1 1} 13}$ The disruptive influence of $\mathrm{Al}$ doping on $\mathrm{ZnO}$ crystal growth is not limited to ECD alone but has also been observed for crystals deposited from solutions via hydrothermal growth. ${ }^{37}$ Also, Käbisch et al. ${ }^{38}$ observed that the nanostructure morphology of $\mathrm{ZnO}$ grown by PLD varied from closely packed hexagonal vertical rods to nano walls when the aluminium content of the nucleation layer was increased from 0 to 2.0 at.\%.

During electrodeposition of $\mathrm{ZnO}$, the $\mathrm{Zn}^{2+}$ ions from the metal salt, combine with $(\mathrm{OH})^{-}$ions from the reduction of $\mathrm{NO}_{3}{ }^{-}$in water. A $\mathrm{Zn}(\mathrm{OH})_{2}$ complex is formed at the cathode and can then be decomposed to $\mathrm{ZnO}$ at temperatures above roughly $50{ }^{\circ} \mathrm{C}$. The results of a previous study of $\mathrm{Zn}$ in $\mathrm{H}_{2} \mathrm{SO}_{4}$ with different impurities suggested that the impurities are 
co-deposited with $\mathrm{Zn}$ at the substrate forming local cells, which enhance hydrogen reduction and zinc dissolution at these points, thus interfering with the deposition at the cathode. ${ }^{39}$ Our CV data of the $99 \%$ purity electrolyte are in agreement with that study since an irreversible oxidation of additional species on the template was observed and it is expected that these species are also active during the deposition which led to $\mathrm{ZnO}$ growth with poor nucleation. Also, notable is the similarity of our film morphology to that of $\mathrm{ZnO}$ made from electrolytes containing sulphates. ${ }^{\mathbf{1 0 4 0}}$ The use of a potentiostatic pre-deposition of zinc to increase the density of nucleation sites led to the subsequent growth of more compact $\mathrm{ZnO}$ films and correlates well with the effect observed by others. ${ }^{5,13}$ It has been reported that lead $(\mathrm{Pb})$ impurities, on the other hand, adsorb on the cathode and promote the deposition of zinc there. ${ }^{\mathbf{4 1}}$ Therefore, the sulphate impurities dominate the disruption of the zinc oxide growth at the cathode from the $99 \% \mathrm{Zn}\left(\mathrm{NO}_{3}\right)_{2}$ electrolyte.

Raman modes corresponding to propagation both parallel and perpendicular to the substrate, were observed in all our films indicating crystalline defects which were also confirmed by the deviation of the relative XRD peak intensities from those of highly crystalline wurtzite $\mathrm{ZnO}$. The addition of aluminium to the electrolyte caused the characteristic ZnO Raman peaks to either broaden or disappear which is a sign of further crystalline structure disorder as confirmed by the disappearance of XRD reflections. The Raman peaks corresponding to LVM1 have been observed in intrinsically doped $\mathrm{ZnO}$ films with high crystalline structural disorder ${ }^{30}$ as well as those with an excess of Zn. ${ }^{42}$ Like in our case, both LVM1 and LVM2 peaks have also been observed by excitation of both intrinsically and extrinsically doped ZnO films. ${ }^{30,42}$ Previously, the LVM1 vibrations were attributed to vibrations of $\mathrm{Zn}_{\mathrm{i}}-\mathrm{N}_{\mathrm{O}}$ complexes ${ }^{43}$ although these modes are also detected in $\mathrm{ZnO}$ films doped by other foreign atoms and have been attributed to vibrations of $\mathrm{Zn}$ atoms caused by lattice disorder induced by impurities. ${ }^{30}$ More detailed theoretical and experimental studies of the Raman spectra of $\mathrm{ZnO}$ using $\mathrm{Zn}$ isotopes have now shown that the LVM1 vibrations involve only $\mathrm{Zn}$ atoms at interstitial sites. ${ }^{\mathbf{4 2}}$ For all the films grown on $\mathrm{ZnO}: \mathrm{Al}$, the LVM1 peaks were probably enhanced by aluminium diffusing from the template into the films that then additionally activated local scattering. This reasoning is also corroborated by the fibrous wall-like morphology of the films which is typical of electrolyte solutions containing aluminium. ${ }^{\mathbf{1 1 , 4 4}}$ The LVM2 peak has been attributed to vibrations of $\mathrm{Zn}_{\mathrm{i}}-\mathrm{O}_{\mathrm{i}}$ complexes ${ }^{42}$ but its intensity in our films is rather weak. However, the absence of appreciable peaks at the $\mathrm{A}_{1}(\mathrm{LO})$ mode at $\left(577 \mathrm{~cm}^{-1}\right)$ and $\mathrm{E}_{1}(\mathrm{LO})$ mode at $\left(588 \mathrm{~cm}^{-1}\right)$ indicates that there is no electron donation from excess zinc and/or oxygen vacancies in all our films. ${ }^{43}$ An oxygen surplus and the presence of defects caused by $\mathrm{O}_{\mathrm{i}}$ sites (and the related breakdown of crystalline order) can be expected in our films since they were grown in an aqueous solution and then heated in air to convert any $\mathrm{Zn}(\mathrm{OH})_{2}$ to $\mathrm{ZnO}$.

Similar to our observation, a previous study reported the simultaneous presence of both the LVM2 peak and an additional mode at $468 \mathrm{~cm}^{-1}$ in $\mathrm{Al}$ doped $\mathrm{ZnO}$ samples and attributed this to phonon modes that are highly localized near the grain boundaries. ${ }^{45}$ As already discussed, oxygen deficiency in our films can be ruled out and therefore the only source for free electrons would be Al doping. These arguments indicate that the $\mathrm{ZnO}$ :Al films grown by electrochemical deposition may be conductive on a microscopic scale but electron transport from one grain to the other is severely restricted by the imperfect crystalline structure.

There is clearly a need to overcome the problem of poor crystalline structure, induced by (sometimes useful) impurities, which until now can only be partially circumvented by adapting the deposition parameters or using substrate activation. The use of additives in the electrolyte to suppress the negative effects of certain impurities, as is done for metal plating, is expected to lead to further improvements in the growth kinetics of $\mathrm{ZnO}$ films grown by electrochemical deposition.

For the extrinsically doped films we can also not rule out, especially for highly crystalline films, that the $\mathrm{Al}^{3+}$ donors may segregate at the surface of the grains which are then compensated by trap states there. ${ }^{46}$ Lastly, it is likely that although wellformed crystalline grains may be formed during ECD, because of the low deposition temperature there is insufficient energy to coalesce the grains together to form a truly compact film as is the case for films grown by highly energetic processes such as sputtering and pulsed laser deposition, or high temperature chemical vapour deposition processes. Additionally, the low electron mobility values reported in the literature (see Table 1) even for apparently well crystallised compact films indicate that electrical charge transport in the lateral direction is limited. However, the successful application of similar films in various types of photovoltaic solar cells, ${ }^{\mathbf{9 , 2 3 , 2 4}}$ despite the poor electrical properties measured using methods probing the charge transport parallel to the substrate, is evidence that they have appreciable carrier mobility in the direction perpendicular to the substrate. One explanation could be that for extrinsically doped ECD grown films ZnO films with grains oriented perpendicular to the substrate, the intra-grain electron mobility is high enough such that the films have a higher conductivity in the transverse direction (perpendicular to the substrate) than in the lateral direction (parallel to the substrate). Such anisotropic electrical transport has also been reported for boron doped $\mathrm{ZnO}$ grown by LPCVD for use as intermediate reflecting layers in multi-junction thin film silicon solar cells. ${ }^{47}$

Solutions to improve the lateral mobility and thus electrical conductivity include post-deposition laser crystallisation of zinc oxide to completely fuse the crystallites $^{48}$ and/or using a different dopant such as gallium or boron.

\section{Conclusions}

Intrinsically and extrinsically doped $\mathrm{ZnO}$ films were grown on both $\mathrm{SnO}_{2}: \mathrm{F}$ and $\mathrm{ZnO}$ :Al templates using galvanic deposition. By use of a potentiostatic activation step, in the cathodic direction prior to galvanic deposition, compact films could be grown from both high purity (99.998\%) and low purity (99\%) $\mathrm{Zn}\left(\mathrm{NO}_{3}\right)_{2}$ electrolytes. Doping of the films was attempted using high purity $(99.999 \%) \mathrm{Al}\left(\mathrm{NO}_{3}\right)_{3}$ as a source of electron donor 
impurities. Although the films were highly transparent, their electrical resistivity was rather high even for those that were compact. By correlating the crystalline structure from XRD, Raman shift studies and the trends in resistivity, we conclude that the poor conductivity of the electrochemically deposited films was caused by structural defects that favour the formation of interstitial complexes that suppress the doping action of aluminium and limit the electron mobility in the direction parallel to the substrate.

\section{Acknowledgements}

The authors thank C. Klimm for acquisition of the SEM images, J. Kavalakkatt for help with the XRD set-up and K. Mack for measuring the transmittance spectra.

\section{Notes and references}

1 H. Tanaka, K. Ihara, T. Miyata, H. Sato and T. Minami, J. Vac. Sci. Technol., A, 2004, 22, 1757-1762.

2 J. N. Duenow, T. A. Gessert, D. M. Wood, T. M. Barnes, M. Young, B. To and T. J. Coutts, J. Vac. Sci. Technol., A, 2007, 25, 955-960.

3 J. Nishino, S. Ohshio and K. Kamata, J. Am. Ceram. Soc., 1992, 75, 3469-3472.

4 M. Izaki, J. Electrochem. Soc., 1997, 144, 1949-1952.

5 B. Canava and D. Lincot, J. Appl. Electrochem., 2000, 30, 711716.

6 H. Ishizaki, M. Izaki and T. Ito, J. Electrochem. Soc., 2001, 148, C540.

7 S. Chatman, L. Emberley and K. Poduska, ACS Appl. Mater. Interfaces, 2009, 1, 2348-2352.

8 J. Rousset, E. Saucedo and D. Lincot, Chem. Mater., 2009, 21, 534-540.

9 J. Rousset and D. Lincot, 34th IEEE Photovoltaic Specialists Conference, 7-12 June 2009, pp. 001246-001251.

10 L. Wang, G. Liu, L. Zou and D. Xue, J. Alloys Compd., 2010, 493, 471.

11 Y. C. Liang, Ceram. Int., 2012, 38, 119-124.

12 T. Shinagawa, M. Chigane, K. Murase and M. Izaki, J. Phys. Chem. C, 2012, 116, 15925-15931.

13 A. C. Aragonès, A. Palacios-Padrós, F. Caballero-Briones and F. Fausto Sanz, Electrochim. Acta, 2013, 109, 117124.

14 M. Thomas and J. Cui, J. Electrochem. Soc., 2013, 160, D213D225.

15 O. Lupan, L. Chow, S. Shishiyanu, E. Monaico, T. Shishiyanu, V. Sontea, B. R. Cuenya, A. Naitabdi, S. Park and A. Schulte, Mater. Res. Bull., 2009, 44, 63-69.

16 M. Miyake, H. Fukui and T. Hirato, Phys. Status Solidi A, 2012, 209, 945-948.

17 M. Wang, J. S. Kim, E. Jungand Chung, E. W. Shin, S. H. Hahn, K. E. Lee and C. Park, Phys. Status Solidi A, 2006, 203, 2418-2425.

18 D. Lincot, MRS Bull., 2010, 35, 778-789.

19 N. Toyama, R. Hayshi, Y. Sonoda, M. Iwata, Y. Miyamoto, H. Otoshi, K. Saito and K. Ogawa, Proceedings of 3rd World
Conference on Photovoltaic Energy Conversion, 2003, pp. 1601-1604.

20 M. Izaki, T. Shinagawa, K.-T. Mizuno, Y. Ida, M. Inaba and A. Tasaka, J. Phys. D: Appl. Phys., 2007, 40, 3326-3329.

21 M. Kemell, F. Dartigues, M. Ritala and M. Leskela, Thin Solid Films, 2003, 434, 20-23.

22 L. Ae, D. Kieven, J. Chen, R. Klenk, T. Rissom, Y. Tang and M. C. Lux-Steiner, Prog. Photovoltaics, 2010, 18, 209-213.

23 B. N. Illy, A. Cruickshank, S. Schumann, R. Da Campo, T. S. Jones, S. Heutz, M. A. McLachlan, D. McComb, D. J. Riley and M. Ryan, J. Mater. Chem., 2011, 21, 12949 (9 pp.).

24 S. Haller, J. Rousset, G. Renou and D. Lincot, EPJ Photovoltaics, 2011, 2, 20401(8 pp.).

25 M. Mizuhashi, Y. Gotoh and K. Adachi, Jpn. J. Appl. Phys., Part 1, 1988, 27, 2053-2061.

$26 \mathrm{PDF}$ 00-041-1445(SnO2), in International Centre for Diffraction Data (ICDD) PDF-2 Database (1998).

27 PDF 00-036-1451(ZnO), in International Centre for Diffraction Data (ICDD) PDF-2 Database (1998).

28 A. Dieguez, A. Romano-Rodroguez, A. Vila and J. R. Morante, J. Appl. Phys., 2001, 90, 1550-1557.

29 J. Calleja and M. Cardona, Phys. Rev. A: At., Mol., Opt. Phys., 1977, 16, 3753.

30 C. Bundesmann, N. Ashkenov, M. Schubert, D. Spemann, T. Butz, E. Kaidashev, M. Lorenz and M. Grundmann, Appl. Phys. Lett., 2003, 83, 1974-1978.

31 E. Kaidashev, M. Lorenz, H. von Wenckstern, A. Rahm, H.-C. Semmelhack, K.-H. Han, G. Benndorf, C. Bundesmann, H. Hochmuth and M. Grundmann, Appl. Phys. Lett., 2003, 82, 3901-3903.

32 M. Miyake, K. Murase, T. Hirato and Y. Awakura, J. Electrochem. Soc., 2003, 150, C413-C419.

$33 \mathrm{~J}$. A. von Windheim, H. Wynands and M. Cocivera, J. Electrochem. Soc., 1991, 138, 3435-3439.

34 J. Sans, J. Sánchez-Royo, A. Segura, G. Tobias and E. Canadell, Phys. Rev. B: Condens. Matter Mater. Phys., 2009, 78, 195105 (9 pp.).

35 W. Tang and D. Cameron, Thin Solid Films, 1994, 238, 83-87. 36 A. P. Roth, J. B. Webb and D. F. Williams, Phys. Rev. B: Condens. Matter Mater. Phys., 1982, 25, 7836-7839.

37 B. Wang, M. Mann, B. Claflin, M. Snure and D. C. Look, Proc. SPIE, 2013, Vol. 8626, 862609 (7 pp.).

38 S. Käbisch, M. Gluba, C. Klimm, S. Krause, N. Koch and N. Nickel, Appl. Phys. Lett., 2013, 103, 103106 (5 pp.).

39 D. Fosnacht and T. J. O'Keefe, J. Appl. Electrochem., 1980, 20, 495.

40 K. Lovchinov, M. Ganchev, M. Petrov, H. Nichev, A. Rachkova, O. Angelov, V. Mikli and D. DimovaMalinovska, Phys. Status Solidi A, 2013, 1-5, DOI: 10.1002/ pssa.201200558.

41 R. Ichino, C. Cachet and R. Wiart, Electrochim. Acta, 1996, 41, 1031.

42 M. A. Gluba, N. H. Nickel and N. Karpensky, Phys. Rev. B: Condens. Matter Mater. Phys., 2013, 88, 245201 (8 pp.).

43 F. Friedrich, M. Gluba and N. Nickel, Appl. Phys. Lett., 2009, 95, 141903 (3 pp.). 
44 G. Exarhos and S. Sharma, Thin Solid Films, 1995, 270, 27-35. 45 M. Tzolov, N. Tzenov, D. Dimova-Malinovska, M. Kalitzova, C. Pizzuto, G. Vitali, G. Zollo and I. Ivanov, Thin Solid Films, 2000, 379, 28-36.

46 A. M. Schimpf, S. T. Ochsenbein, R. Buonsanti, D. J. Milliron and D. R. Gamelin, Chem. Commun., 2012, 48, 9352-9354.
47 G. Bugnon, T. Söderström, S. Nicolay, L. Ding, M. Despeisse, A. Hedler, J. Eberhardt, C. Wachtendorf and C. Ballif, Sol. Energy Mater. Sol. Cells, 2011, 95, 2161-2166.

48 H. Pan, N. Misra, S. H. Ko, C. P. Grigoropoulos, N. Miller, E. E. Haller and O. Dubon, Appl. Phys. A, 2009, 94, 111115. 